\title{
«Немецкая Казань»: имагологический анализ художественных произведений Гузель Яхиной
}

\section{“German Kazan”: Imagological Analysis of Guzel Yakhina’s Literary Works}

\begin{abstract}
The capital of the Republic of Tatarstan is a multicultural city. It is a combination of "Russian," "Tatar" and, not least, "German elements". The writer Guzel Yakhina has repeatedly addressed this cultural diversity in her literary works. In them a native of Kazan explores the past and present of the city. Excellent knowledge of German language and culture allows her to study in detail the "German trace" in the history of the capital of Tatarstan to determine its status. The article offers a brief imagological analysis of the images of "German Kazan" presented in the novel Zuleikha and the essay Garden on the Border, or the Garden "Russian Switzerland". The imagological study conducted at the macro-, meso- and micro-levels shows that in Yakhina's literary works the images of "German Kazan" are equivalent to the images of "Russian Kazan" or "Tatar Kazan." The "German elements" are firmly rooted in the texture of the city and have been an integral part of its cultural code for several centuries. At the same time, following the novel and the essay, they do not have the status of an exotic "foreign," but a familiar "other."
\end{abstract}

Keywords: Guzel Yakhina, the image of German Kazan, Zuleikha, Garden on the Border, or the Garden "Russian Switzerland", imagological analysis, hetero-image

Ключевые слова: Гузель Яхина, образ немецкой Казани, Зулейха открывает глаза, Сад на границе, или Сад «Русская Швейцария», имагологический анализ, гетерообраз

\section{„Niemiecki Kazań”: imagologiczna analiza utworów Guzel Jachiny}

Streszczenie: Stolica Republiki Tatarstanu to miasto wielokulturowe. To połączenie „rosyjskiego”, „tatarskiego” i, co nie mniej ważne, „niemieckiego” pierwiastka. Pisarka Guzel Jachina wielokrotnie odnosiła się do tej różnorodności kulturowej w swoich tekstach literackich. Rdzenny mieszkaniec Kazania odkrywa w nich przeszłość i teraźniejszość miasta. Doskonała znajomość języka i kultury niemieckiej pozwala autorce na szczegółowe zbadanie „niemieckiego śladu" w historii stolicy Tatarstanu w celu określenia jego statusu. Artykuł zawiera krótką analizę imagologiczną obrazów „niemieckiego Kazania”, przedstawionych w powieści Zulejka 
otwiera oczy i eseju Ogród na granicy, czyli Ogród „,Rosyjska Szwajcaria”. Badania imagologiczne, przeprowadzone na poziomach makro-, mezo- i mikro-, pokazują, że w dziełach literackich Jachiny obrazy „niemieckiego Kazania” są równoważne obrazom „rosyjskiego Kazania” czy „tatarskiego Kazania”. „Elementy niemieckie” są mocno zakorzenione w strukturze miasta i od kilku stuleci stanowią integralną część jego kodu kulturowego. Jednocześnie, w powieści i eseju, nie mają one statusu egzotycznego Obcego, ale znajomego Innego.

Słowa kluczowe: Guzel Jachina, obraz niemieckiego Kazania, Zulejka otwiera oczy, Ogród na granicy, czyli Ogród „,Rosyjska Szwajcaria”, analiza imagologiczna, heteroobraz

Образы Казани в русской литературе встречаются довольно часто ${ }^{1}$. Ещё более частым является изображение русскими писателями Германии и немцев - обращение к данной тематике имеет давнюю традицию². В то же время, куда более редко в одном произведении встречаются, на первый взгляд, плохо совместимые между собой русские, татарские и немецкие мотивы. Между тем, такое сосуществование оправдано исторически.

Гузель Яхина - одна из литераторов, обратившихся в своём творчестве к немецкому прошлому столицы Республики Татарстан. Сразу в нескольких произведениях писательница обращается к насыщенной истории родного города, главным образом первой половины XX в., и воспоминаниям о детстве и юности ${ }^{3}$. Она также живо интересуется историей российских преимущественно поволжских ${ }^{4}-$ немцев $^{5}$. В библиографии Яхиной особое место занимают произведения, сочетающие серьёзное исследование Казани и её «немецких элементов», -исторический роман Зулейха открывает глаза (2015) и ностальгическое эссе ${ }^{6}$ Сад на границе, или Сад «Русская Швейцария» (2016). Если в эссе автор приглашает читателя на прогулку в прошлое по любимому городу и парку, то в романе, помимо Казани, немало внимания уделено судьбе профессора Казанского университета Вольфа

1 Можно назвать три, пожалуй, самых известных примера: Капитанская дочка А.С. Пушкина, Мои университеть М. Горького, Гадюка А.Н. Толстого.

2 Список подобных произведений невероятно обширен. Вот лишь некоторые, на наш взгляд, особенно важные примеры за последние три столетия: Пиковая дама А.С. Пушкина, Ася И.С. Тургенева (XIX в.); Жизнь и судьба В.С. Гроссмана, Генерал и его армия Г.Н. Владимова (ХХ в.); Авиатор Е.Г. Водолазкина, Гусь Фриц С.С. Лебедева (XXI в.).

3 К таковым относятся рассказ Мотылёк (2014), эссе Деревянные дома (2018) и роман Эиелон на Самарканд (2021).

4 В 1923-1941 годах в СССР существовала Автономная Социалистическая Советская Республика Немцев Поволжья.

5 Здесь следует упомянуть рассказ Винтовка (2015) и роман Дети мои (2018).

6 Чаще всего это произведение определяется как рассказ, однако мы - вслед за автором произведения - воспринимаем его как эссе (См., напр., Книжный магазин МОСКВА, Презентация книги «Все в саду»! [15.06.2016], https://www.youtube.com/watch?v=AfSXeT_meKE (доступ: 29.01.2021)). Жанровая характеристика эссе предполагает «прозаическое сочинение небольшого объема и свободной композиции, выражающее индивидуальные впечатления и соображения по конкретному поводу или вопросу и заведомо не претендующее на определяющую или исчерпывающую трактовку предметы» (В.С. Муравьев, Эссе [в:] Литературная энциклопедия терминов и понятий, гл. ред. и сост. А.Н. Николюкин, Москва 2001, с. 1246-1247). 
Карловича Лейбе. Данные произведения выбраны в качестве объектов имагологического анализа, направленного на изучение образов «немецкой Казани» сквозь призму субъективного восприятия представителями иных культур.

Согласно немецкому литературоведу Манфреду Беллеру:

Literary (...) imagology studies the origin and function of characteristics of other countries and peoples, as expressed textually, particularly in the way in which they are presented in works of literature, plays, poems, travel books and essays ${ }^{7}$.

Главную задачу имагологии учёный видит в следующем: «(...) to describe the origin, process and function of national prejudices and stereotypes, to bring them to the surface, analyse them and make people rationally aware of them ${ }^{8}$. В имагологии образ - это «the mental silhouette of the other, who appears to be determined by the characteristics of family, group, tribe, people or race ${ }^{9}$. Образу свойственны эмоциональная окраска, многомерность, динамичность. Опираясь, в основном, на выборочные оценочные суждения и наблюдения, он оказывает значительное воздействие на наше восприятие другой страны, культуры, народа. Вместе с тем необходимо отделять автообраз (восприятие собственной общности) от гетерообраза (восприятие другой общности). Автообразу скорее присуще нарочито позитивное восприятие, в то время как гетерообразу - настороженно негативное ${ }^{10}$.

При проведении анализа образов «немецкой Казани» в произведениях Яхиной мы будем ориентироваться на адаптированную к задачам нашего исследования методологию, предложенную Йоэпем Леерссеном ${ }^{11}$. Имагология не рассматривает литературный текст в отрыве от контекста и интертекста. Этим обусловлена необходимость т.н. «внешнего анализа»: краткого предоставления биографии писательницы (с акцентом на её связях с немецкой культурой и Германией), описания исторического, социального и политического контекстов анализируемых произведений, а также истории их создания. Предметом т.н. «внутреннего анализа» станут непосредственно тексты произведений. В нём, во-первых, будут представлены образы «немецкой Казани» на макро- (город в обоих текстах), мезо- (городской парк в эссе) и микроуровне (казанский немец в романе); во-вторых, исследованы возможные интертекстуальные связи; в-третьих, установлены функции данных гетерообразов внутри художественных текстов. В завершении мы попытаемся определить специфику образов «немецкой Казани» в соответствующих произведениях Яхиной, установить их сверхзадачу.

${ }^{7}$ M. Beller, Perception, Image, Imagology [в:] Imagology. The Cultural Construction and Literary Representation of National Characters. A Critical Survey, eds. M. Beller, J. Leerssen, AmsterdamNew York 2007, c. 7.

${ }^{8}$ Ibid., c. $11-12$.

${ }^{9}$ Ibid., c. 4.

${ }^{10}$ См. ibid., c. 4-5; A. Nowakowski, W Kraju Tysiaca Jezior. Obraz Finlandii w rosyjskiej literaturze podróżniczej (1809-1917), Krosno 2018, c. 41-42.

${ }^{11}$ См. J. Leerssen, Imagology: On Using Ethnicity to Make Sense of the World, «Iberic@1, Revue d'études ibériques et ibéro-américaines» 2016, No. 10, c. 19-21. 


\section{Биографическая справка}

Гузель Яхина родилась в 1977 году в мультикультурной Казани в интеллигентной татарской семье. По признанию писательницы, почти всю жизнь она «ощущала себя в какой-то мере на границе между русской, татарской и немецкой культурами» ${ }^{12}$. В раннем детстве девочка говорила исключительно на татарском языке, позднее основным для неё стал русский. Любовь к немецкому языку ей привил дедушка, учитель немецкого. После окончания школы Яхина поступила на факультет иностранных языков Казанского государственного педагогического института. В 1995 году, будучи студенткой, она полгода училась в Боннском университете. После получения диплома учителя немецкого и английского языков некоторое время работала переводчиком. С 1999 года живёт в Москве. В 2013 году Яхина поступила на факультет сценарного мастерства Московской школы кино. Написанный во время учёбы сценарий лёг в основу её дебютного романа Зулейха открывает глаза, отмеченного специалистами и читателями (литературные премии «Большая книга» и «Ясная поляна»; статус «бестселлера»; театральные постановки; экранизация). Роман, от идеи до выхода в свет которого в общей сложности прошло около четырёх лет (20112015), переведён на многие языки, в том числе и на немецкий. В 2015 году Яхина написала эссе Сад на границе, или Сад «Русская Швейцуария» (первая публикация - 2016 год, апрельский номер журнала «Сноб», затем в коллективном сборнике Все в саду [2016]) $)^{13}$.

\section{Контекст}

Казань на протяжении веков отличалась пестротой национального и конфессионального состава населения. Политика Екатерины II способствовала в XVIII в. массовому заселению немецкими колонистами территорий Поволжья. Некоторые из них впоследствии осели в Казани. Открытие Императорского Казанского университета в 1804 году послужило поводом для приезда высококвалифицированных специалистов (учёных, врачей, архитекторов и т.д.) немецкого происхождения. К началу XX в. немцы составляли $0,8 \%$ жителей Казани, оказывая при этом значительное влияние на научную, культурную и экономическую жизнь города. Они мирно сосуществовали с представителями других национальностей. С началом Первой мировой войны Российскую империю захлестнули германофобия и шпиономания. Во время Второй мировой войны гонение

12 А. Тверитина, Аскетичное поглощчение. Гузель Яхина о немецкой мифологии, ощущении свободы и жутком, но прекрасном месте, «Бортовой журнал Аэрофлот» 2019, Ноябрь, с. 40.

${ }^{13}$ См. ibid.; П. Сурнина, Гузель Яхина: «В моей жизни было очень много немецкого», «Бортовой журнал Utair» 2019, Август, с. 24-26. 
на немецкое население города продолжилось с новой силой ${ }^{14}$. В 1989 году удельный вес немцев в Татарстане составлял $0,1 \%$ (2775 человек); подобное положение вещей зафиксировала и Всероссийская перепись населения 2010 года $(0,1 \%-2200 \text { человек })^{15}$.

Российско-германские отношения в период с 2011 до весны 2014 года развивались плодотворно и всесторонне, однако политический кризис на Украине, приведший к спорному международному статусу Крымского полуострова и вооружённому противостоянию на востоке Украины, стал катализатором для введения целого ряда экономических санкций и контрсанкций между Европейским союзом и Российской Федерацией ${ }^{16}$. Это отразилось и на динамике российско-германских отношений: продолжающийся с весны 2014 года тяжёлый кризис негативно сказывается и на отношении россиян к Германии и её жителям ${ }^{17}$.

\section{Макроуровень - город Казань}

В романе Зулейха открывает глаза представлены описания Казани, охватывающие период 2-ой половины XIX - 1-ой половины XX вв. Воображение неграмотной крестьянки Зулейхи рисует татарскую столицу огромной, славной своими мастерами. При строительстве банной печи её муж делает заказ именно там:

На казанском заводе прусского фабриканта Дизе [Муртаза] заказал по размерам стальной бак - и поставил его точно на предназначенный крутой уступ, гладко примазал глиной. Такая печь и баню топила, и воду грела быстро, только успевай подтапливать, - загляденье, а не печь ${ }^{18}$.

Стереотип о немецком качестве в русской литературе крайне устойчив и по-прежнему актуален. Кпримеру, его можно обнаружить в повести Невский проспект Николая Гоголя и в пьесе Безденежье Ивана Тургенева ${ }^{19}$. В романе Яхиной качественно выполненный заказ в меньшей степени ассоциируется с национальностью фабриканта, нежели с его местожительством: образ

14 См. Т. Валиди, Г. Рафикова, «Русские» немиьы в Казани в годы Первой мировой войны: неизбежность трагедии, «Гасырлар авазы - Эхо веков» 2014, № 1-2, с. 143.

15 См. Территориальный орган Федеральной службы государственной статистики по Республике Татарстан, Всероссийская перепись населения-2010, https://tatstat.gks.ru/folder/39222 (доступ: 30.01.2021).

${ }^{16}$ См. А.В. Багай, Российско-германские отношения «после Крылм»: от «Партнерства для модернизащии» до деградации диалогических форматов, «Вестник Санкт-Петербургского университета. Международные отношения» 2019, Т. 12, Вып. 3.

17 См., напр., Посольство России в Федеративной Республике Германия, Опрос ВЦИОМ по вопросу германо-российских отношений [24.09.2015], https://russische-botschaft.ru/ru/2015/09/24/ opros-vciom-po-voprosu-germano-rossiy/ (доступ: 30.01.2021).

18 Г.Ш. Яхина, Зулейха открыввает глаза, Москва 2016, с. 27-28.

19 См. Е.В. Папилова, Художественная имагология: немцы глазами русских (на материале литературы XIX в.), Дис. ...канд. филол. н., Москва 2013, с. 110. 
Казани противопоставлен деревне Юлбаш (родине Зулейхи), тем самым реализуется антитеза «город-деревня».

В непосредственных описаниях самой столицы Красной Татарии, её «немецкий образ» напрямую не упоминается. Так, например, строгий сотрудник Казанского ГПУ Иван Игнатов с осуждением осматривает причудливое, по его мнению, здание железнодорожного вокзала и отмечает его несоответствие современной миссии:

Здание вокзала - как печатный пряник: шоколадно-красное, вкусно облепленное башенками и окошками, украшенное гербами и вазами, обсыпанное блестками черепицы, утыканное шпилями и флюгерами. Игнатов морщится: казанский вокзал окно в Сибирь для всей России, а выглядит как дворец культуры или музей какой. Тьфу, одним словом ${ }^{20}$.

Архитектором здания вокзала был российский немец Генрих Руш (18551905). Впрочем, в приведённом фрагменте внимание на «немецком следе» в истории города не заостряется - это прежде всего пример конфронтации наследия Российской империи (здание вокзала было открыто в 1896 году) с советской действительностью (сотрудник ГПУ Игнатов).

Представленный в эссе Сад на гранище, или Сад «Русская Швейцария» образ Казани, начиная с XVIII и заканчивая началом XXI вв., вновь подтверждает встроенность «немецких элементов» в ткань татарской столицы. Особенно показательны короткие описания Казани 1990-х и 2010-х годов: «немецкий образ» города существует на равных правах с «русским» и «татарским», не вступая с ними в противоречие. Хаос переходного времени 1990-х годов отражается в этих образах в одинаковой степени. Однако даже пребывая в сюрреалистичном беспорядке, немецкая, русская и татарская Казани остаются в тесной связи, удивительным образом перетекая друг в друга. Автор эссе вспоминает:

Фехтованием я занимаюсь в кирхе Святой Екатерины. Пирожками перекусываю во Введенской церкви, их там отменно жарят. В мечеть Нурулла, что у Сенного базара, забегаю по дороге в институт и учу немецкий $(. . .)^{21}$.

В 2010-е годы, когда в России обозначается порядок, (почти всем) православным, мусульманским и лютеранским архитектурным сооружениям возвращается первоначальное предназначение. Их гармоничное добрососедство не ставится автором эссе под сомнение:

Заходила недавно во Введенскую церковь (теперь это музей, пирожки там давно не жарят) и в кирху Святой Екатерины (теперь это снова кирха (...)). В мечеть Нурулла, что у Сенного базара, меня не пустили - теперь женщинам туда вход воспрещен ${ }^{22}$.

${ }^{20}$ Г.Ш. Яхина, Зулейха..., ор. cit., с. 148-149.

${ }^{21}$ Eadem, Сад на граниие, или Сад «Русская Швейияария» [в:] Все в саду, сост. Е.Д. Шубина, С.И. Николаевич, Москва 2016, с. 55.

${ }^{22}$ Ibid., c. 64. 


\section{Мезоуровень - городской парк}

Впрочем, в эссе Яхиной всё же встречается противопоставление русского и немецкого миров. В своеобразном реквиеме Центральному парку культуры и отдыха им. Горького - парку «счастливого советского детства» ${ }^{23}$ автор рассказывает о его истории. На дореволюционных картах он был обозначен как Сад «Русская Швейцария». Диковинное название сад получил из-за ландшафта: «Могучие, крытые пышной зеленью холмы, причудливые овраги, крутой изгиб реки [Казанки] сквозь еловые ветви блестит и правда, чем не милая русской душе альпийская заграница?» ${ }^{24}$. C XIX в. эта территория превратилась в излюбленное место отдыха у казанцев. Там стали возникать

(...) дорожки-беседки, столики-скамейки, благородные гипсовые статуи, ресторациикондитерские, кабаки-трактиры, шалманы-балаганы, механический театр, эстрада с шансонетками, цирк шапито с гуттаперчевыми акробатами, тараканьи бега и широко рекламируемые почтенной публике собачьи концерты! Как говорится, хоть и Швейцария, а всё ж - наша, рассейская! 25

Чуть позднее соседние с садом холмы были застроены домамидачами местной немецкой интеллигенции, а район прозвали Немецкой Швейцарией: «В этой части сада, в отличие от русской, всё чинно и очень респектабельно. Можно расслышать, как журчат меж аккуратных дачных домиков облагороженные заботливой германской рукой ручьи» ${ }^{26}$. При изображении Немецкой Швейцарии Яхина использует типичные для немецкой ментальности мотивы: чинность, респектабельность, аккуратность, облагороженность, заботливость. Они настолько частотны в русской литературе, что их можно причислить к межтекстуальным «имагологическим мотивам» (термин Е.В. Папиловой $)^{27}$. Тем не менее, несмотря на противопоставление и контраст, функции русской и немецкой Швейцарий в эссе Яхиной опрометчиво объяснять только лишь оппозицией «свои-чужие». Помня о национальной принадлежности писательницы, гораздо резоннее говорить об отстранённой, лишённой этноцентризма и национального противоборства паре «другие (русские) - другие (немцы)». Обе части сада образуют единое целое и представляют один из полюсов куда более явно проявляющейся в эссе антитезы «герметичный сад (Швейцария/ рай/здоровье) - остальной город (Россия/ад/болезни)»:

Так и живут они рядом - два разных мира с общей границей, одной оградой и одним названием на двоих. Там, за пределами сада, пусть остаются грязь немощеных улиц, туберкулезная сырость татарских слобод, заболоченные и полные нечистот городские

23 Ibid., c. 60.

${ }^{24}$ Ibid., c. 57.

25 Ibid.

${ }^{26}$ Ibid., c. $57-58$.

27 К примеру, эти мотивы можно встретить в произведениях А.С. Пушкина (Евгений Онегин), В.И. Даля (Колбасники и бородачи), Н.В. Гоголя (Невский проспект) (См. Е.В. Папилова, Художественная имагология..., ор. cit., с. 108-110). 
озера, нищие, калики, клопы, комары, каторжане с их колодками и кандалами... Здесь ничего этого нет. Здесь - только радость, жизнь, вечный праздник. Здесь Швейцария ${ }^{28}$.

Судьба сада всецело подчинена историческим эпохам. Русская Швейцария проявила большую жизнестойкость: в 1936 году она была преобразована в образцовый советский парк. Немецкая Швейцария, по понятным причинам, потеряла своё название, пришла в запустение. Первая служит культурному отдыху и идеологическому воспитанию советских граждан; «заросшие бурьяном просторы» ${ }^{29}$ второй удачно скрывают от гуляющих неприятную правду - тюремную психиатрическую больницу. Для советских же детей граница между двумя частями дореволюционного сада условна, легко преодолима:

Мы [жившие неподалеку дети] были - парковые. Мы не признавали границ и торных троп - прокладывали по холмам свои пути, вдоль и поперек мощеных дорожек, просачивались во все щели и дырки в заборах, проникали всюду. (...) На пугачевских липах мы сооружали тайные убежища. На прогалинах бывшей Немецкой Швейцарии жгли костры ${ }^{30}$.

Символично, что в начале XXI в. центральный парк Казани, под натиском цивилизации и природы, оказался на грани полного исчезновения. Представляется закономерным, что вслед за «умиранием» Немецкой Швейцарии схожая участь неминуемо ожидала и её постоянную спутницу Русскую Швейцарию.

\section{Микроуровень - казанский немец}

Вольфу Карловичу Лейбе, герою романа Зулейха открывает глаза, на момент ареста и отправки в 1930 году на каторгу 55 лет. Он родился в Казани, был профессором Казанского университета в третьем поколении. Ещё будучи молодым хирургом, Лейбе прославился на всю губернию. У него неординарная внешность, что при конвоировании отмечает 30-летняя Зулейха:

(...) черты лица - изящные, как у юноши; кудрявая седина - яркая, серебряная; и даже морщины - тонкие, умные. Длинная многонедельная щетина закрывает щеки, придает благородства. (...) Только одет странно, как нищий, - в очень ветхий, проеденный молью и рваный во многих местах старинный мундир синего цвета, на обмотанных тряпьем ногах - домашние тапочки без задников ${ }^{31}$.

Последовавшие за революцией 1917 года события пагубно отразились на психическом здоровье профессора. Около десяти лет он мысленно живёт в яйце, которое, искажая реальность, надёжно оберегает его от потрясений:

\footnotetext{
${ }^{28}$ Г.Ш. Яхина, Сад на границее..., ор. cit., с. 58.

29 Ibid., c. 59.

30 Ibid., c. 60-61.

31 Eadem, Зулейха..., ор. cit., с. 157.
} 
Вольф Карлович не заметил перемен и в собственной квартире: шумных и обогащенных многочисленным потомством подселенных жильцов, исчезновения большей части фамильного серебра и мебели, отсутствия отопления зимой и отключения газа в рожках. Он жил, не покидая отцовского кабинета и направляя скупые остатки душевного тепла на любимого и беззаветного друга, верного и единственного спутника - на драгоценное яйцо ${ }^{32}$.

Даже пребывая в полубезумном состоянии, профессор медицины отличается любознательностью, педантичностью, решительностью в экст-ренных ситуациях. Он любезен, предельно вежлив, никогда не теряет чувства собственного достоинства. Глубокие знания, аналитический склад ума и наблюдательность делают его отличным диагностом. Его национальное происхождение даёт о себе знать лишь в редких немецких словах. В глазах окружающих Лейбе прежде всего чудаковатый учёный, беспомощный в быту интеллигент, представитель дореволюционной России. Ярлык «германский шпион» вешается на него исключительно ради достижения корыстных целей (домработница мечтает завладеть его комнатой) и выполнения плана (казанское ГПУ организует арест и допрос предполагаемого врага). Профессор Лейбе плохо соответствует образам врачей-немцев из классической русской

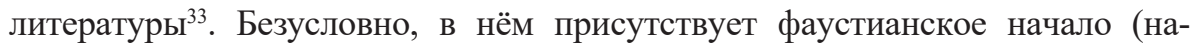
пример, «его донельзя, до зуда в кончиках пальцев, волновала тайна человеческого рождения ${ }^{34}$ ), но в куда большей мере он проявляет сходство со своим московским коллегой из повести Михаила Булгакова Собачье сердие - профессором Преображенским. Семикомнатная квартира в обоих случаях становится для их владельцев причиной бед. Как «раскулаченного» (а вовсе не как «германского шпиона») 35 его на общих для всех арестантов условиях отправляют в сибирскую тайгу на верную гибель. Преодолев свой психический недуг, Лейбе не только выживает в суровых климатических условиях, но и, в отличие от ленинградских интеллигентов, оставаясь при этом верным своим принципам, добивается всеобщего уважения и даже повышения (в 1946 году он возглавит районную больницу). Причину такого успеха следует искать вовсе не в «немецком национальном характере», предлагающем определённую модель поведения, а в уникальном умении казанского немца приспосабливаться к тяжёлым обстоятельствам и в его фанатичном отношении к медицине.

${ }^{32}$ Ibid., c. 258 .

${ }_{33}$ См. Д.А. Салимова, Образ российского немца в русскоязычной литературе (на примере текста автора-татарки), «Гуманитарные науки и образование» 2017, № 2 (30), с. 131.

${ }^{34}$ Г.Ш. Яхина, Зулейха..., ор. cit., с. 111.

${ }^{35}$ В ходе серии допросов следователь областного ГПУ Бутылкин так и не добьётся от полубезумного профессора признания в шпионаже в пользу Германии. Сначала будет решено отправить арестованного в психиатрическую лечебницу, но затем, ради «улучшения» показателей коллективизации и раскулачивания, Лейбе будет переведён в разряд кулаков (см. ibid., c. 131). 


\section{Резюме}

Проведённый имагологический анализ указываетнато, что образы «немецкой Казани» в романе и эссе Яхиной не являются чем-то чужеродным в общей картине города; они скорее демонстрируют знакомое «другое». «Немецкие» элементы (здания, парк, жители) полностью интегрированы и наравне с «русскими» и «татарскими» элементами уже на протяжении нескольких столетий представляют собой неотъемлемую часть культурного кода Казани, и шире - России. Описывая их, российская писательница, как правило, старается избегать антитезы «свои-чужие» и национальных стереотипов. Национальная принадлежность - лишь деталь, которая во времена государственных потрясений (коллективизация, войны) может нанести вред; обычно же на неё почти не обращают внимания. В период кризиса в российско-германских отношениях Яхина, на примерах своих художественных текстов, предлагает не отгораживаться друг от друга заборами и искать внутренних врагов, а наладить межнациональный диалог. Обращаясь к «немецкому образу» родного города, она выступает посредником между культурами, призывающим к гуманности.

\section{Библиография (References)}

Багай А.В., Российско-германские отночения «после Крыма»: от «Партнерства для модернизации» до деградаџии диалогических форматов, «Вестник Санкт-Петербургского университета. Международные отношения» 2019, Т. 12, Вып. 3.

Валиди Т., Рафикова Г., «Русские» немщь в Казани в годы Первой мировой войны: неизбежность трагедии, «Гасырлар авазы - Эхо веков» 2014, № 1-2.

Книжный магазин МОСКВА, Презентация книги «Все в саду»! [15.06.2016], https://www.youtube.com/watch?v=AfSXeT_meKE (доступ: 29.01.2021).

Муравьев В.С., Эссе [в:] Литературная энцииклопедия терминов и понятий, гл. ред. и сост. А.Н. Николюкин, Москва 2001.

Папилова Е.В., Художественная имагология: немиь глазами русских (на материале литературы XIX в.), Дис. ...канд. филол. н., Москва 2013.

Посольство России в Федеративной Республике Германия, Опрос ВЦИОМ по вопросу германо-российских отношений [24.09.2015], https://russische-botschaft. ru/ru/2015/09/24/opros-vciom-po-voprosu-germano-rossiy/ (доступ: 30.01.2021).

Салимова Д.А., Образ российского немияа в русскоязычной литературе (на примере текста автора-татарки), «Гуманитарные науки и образование» 2017, № 2 (30).

Сурнина П., Гузель Яхина: «В моей жизни было очень много немецкого», «Бортовой журнал Utair» 2019, Август.

Тверитина А., Аскетичное поглощееие. Гузель Яхина о немецкой мифологии, ощущении свободы и жутком, но прекрасном месте, «Бортовой журнал Аэрофлот» 2019, Ноябрь. 
Территориальный орган Федеральной службы государственной статистики по Республике Татарстан, Всероссийская перепись населения-2010, https:/tatstat.gks.ru/folder/39222 (доступ: 30.01.2021).

Яхина Г.Ш., Зулейха открывает глаза, Москва 2016.

Яхина Г.Ш., Сад на границе, или Сад «Русская Швейияария» [в:] Все в саду, сост. Е.Д. Шубина, С.И. Николаевич, Москва 2016.

Beller M., Perception, Image, Imagology [в:] Imagology. The Cultural Construction and Literary Representation of National Characters. A Critical Survey, eds. M. Beller, J. Leerssen, Amsterdam-New York 2007.

Leerssen J., Imagology: On Using Ethnicity to Make Sense of the World, «Iberic@1, Revue d'études ibériques et ibéro-américaines» 2016, No. 10.

Nowakowski A., W Kraju Tysiąca Jezior. Obraz Finlandii w rosyjskiej literaturze podróżniczej (1809-1917), Krosno 2018.

\section{References}

Bagay A.V., Rossiysko-germanskiye otnosheniya "posle Kryma": ot "Partnerstva dlya modernizatsii" do degradatsii dialogicheskikh formatov, "Vestnik Sankt-Peterburgskogo universiteta. Mezhdunarodnyye otnosheniya" 2019, T. 12, Vyp. 3.

Beller M., Perception, Image, Imagology [v:] Imagology. The Cultural Construction and Literary Representation of National Characters. A Critical Survey, eds. M. Beller, J. Leerssen, Amsterdam-New York 2007.

Knizhnyy magazin MOSKVA, Prezentatsiya knigi "Vse v sadu"! [15.06.2016], https://www.youtube.com/watch?v=AfSXeT_meKE (access: 29 Jan 2021).

Leerssen J., Imagology: On Using Ethnicity to Make Sense of the World, "Iberic@1, Revue d'études ibériques et ibéro-américaines" 2016, No. 10.

Murav'yev V.S., Esse [v:] Literaturnaya entsiklopediya terminov i ponyatiy, gl. red. i sost. A.N. Nikolyukin, Moskva 2001.

Nowakowski A., W Kraju Tysiąca Jezior. Obraz Finlandii w rosyjskiej literaturze podróżniczej (1809-1917), Krosno 2018.

Papilova Ye.V., Khudozhestvennaya imagologiya: nemtsy glazami russkikh (na materiale literatury XIX v.), Dis. ...kand. filol. n., Moskva 2013.

Posol'stvo Rossii v Federativnoy Respublike Germaniya, Opros VTSIOM po voprosu germano-rossiyskikh otnosheniy [24.09.2015], https://russische-botschaft.ru/ ru/2015/09/24/opros-vciom-po-voprosu-germano-rossiy/ (access: 30.01.2021).

Salimova D.A., Obraz rossiyskogo nemtsa v russkoyazychnoy literature (na primere teksta avtora-tatarki), „Gumanitarnyye nauki i obrazovaniye” 2017, no. 2 (30).

Surnina P., Guzel' Yakhina: "V moyey zhizni bylo ochen" mnogo nemetskogo', "Bortovoy zhurnal Utair" 2019, Avgust.

Territorial'nyy organ Federal'noy sluzhby gosudarstvennoy statistiki po Respublike Tatarstan, Vserossiyskaya perepis' naseleniya-2010, https://tatstat.gks.ru/folder/39222 (access: 30.01.2021).

Tveritina A., Asketichnoye pogloshcheniye. Guzel' Yakhina o nemetskoy mifologii, oshchushchenii svobody $i$ zhutkom, no prekrasnom meste, "Bortovoy zhurnal Aeroflot" 2019, Noyabr'. 
Validi T., Rafikova G., "Russkiye” nemtsy v Kazani v gody Pervoy mirovoy voyny: neizbezhnost' tragedii, "Gasyrlar avazy - Ekho vekov" 2014, no. 1-2.

Yakhina G.Sh., Sad na granitse, ili Sad "Russkaya Shveycariya" [v:] Vse v sadu, sost.

E.D. Shubina, S.I. Nikolayevich, Moskva 2016.

Yakhina G.Sh., Zuleykha otkryvayet glaza, Moskva 2016. 